Review Article

$\mathrm{J}$ Exp Clin Med

2021; 38(S1): 38-43

doi: $10.52142 /$ omujecm.38.si.gastro.5

\title{
Management of patients with occult gastrointestinal bleeding
}

\author{
Ahmet Bektaş ${ }^{1, *}$ (i) \\ ${ }^{1}$ Department of Gastroenterology, Faculty of Medicine, Ondokuz Mayis University, Samsun, Turkey
}

\begin{abstract}
\begin{tabular}{ccccc}
\hline Received: 20.07 .2020 & $\bullet$ & Accepted/Published Online: 11.11 .2020 & $\bullet$ & Final Version: 18.03 .2021 \\
\hline
\end{tabular}
Abstract

The majority of cases of occult bleeding are found in the course of colorectal cancer screening or during the evaluation of iron deficiency anemia. In up to half of all patients with occult GI bleeding, the source will not be found on initial endoscopic evaluation. Occult gastrointestinal bleeding is an issue with difficulties in diagnosis and treatment. It may come to the clinic as asymptomatic, detected in routine screenings or as iron deficiency of unknown etiology. In recent years, there have been great advances in the diagnosis and treatment. Capsule endoscopy and enteroscopy have provided these advances. However, the problem is not fully resolved. Additional developments are needed in this regard. In this review, the management of patients with occult gastrointestinal bleeding is explained in the light of the latest literature findings.
\end{abstract}

Keywords: occult, bleeding, gastrointestinal, management

\section{Introduction}

Iron deficiency anemia and gastrointestinal (GI) bleeding are common sources of referral to Gastroenterologists. Gastrointestinal bleeding (GIB) may be overt, obscure or occult. Overt bleeding is blood loss that is visible to the patient or clinician which manifests as hematemesis, melena or hematochezia. Obscure GIB is defined as persistent or recurrent bleeding for which no definitive source has been identified by an initial evaluation. Obscure GIB may be occult, if not visible or overt if it manifests with a continued passage of visible blood.

In most large series, the cause of bleeding is not found on EGD and colonoscopy in 5\% of hospitalized patients with overt GI bleeding. In $75 \%$ of these patients, a bleeding site is located in the small intestine. Occult gastrointestinal bleeding refers to the initial presentation of a positive fecal occult blood test result and/or iron deficiency anemia when there is no evidence of visible blood loss to the patient or physician. The management of suspected bleeding consists of a judicious search for the cause of bleeding, which should be guided by the clinical history, physical findings, and the results of any previous evaluations and treatment with the appropriate method (Perencevich and Saltzman, 2020).

\section{Fecal occult blood tests}

There are two types of fecal occult blood tests generally used, which are immunochemical and guaiac-based stool tests.

\subsection{Fecal immunochemical test (FIT) for blood}

FIT directly measures hemoglobin in the stool. FIT is performed on a small sample of stool that the patient provides in a special container and does not require restrictions to medications or diet prior to providing the sample. FIT is made quantitatively using standardized automated analyzers and has the potential to produce more consistent results, with a higher PPV (Park et al., 2012; Huang et al., 2014; Doubeni, 2020). It should be done within 24 hours of collection, because FIT sensitivity declines with delayed testing due to degradation of hemoglobin.

FIT requires only one sample rather than three days of samples as for guaiac-based fecal occult blood testing (gFOBT). FIT is more sensitive than gFOBT for colonic lesions (Young et al., 2015; Robertson et al., 2017). In addition, a positive FIT has high specificity for lower gastrointestinal bleeding. FIT appears to be less sensitive for detection of rightsided than of left-sided colonic lesions (Wong et al., 2015). Fecal immunohistochemical testing detects only human globin and therefore does not detect upper GI bleeding due to digestion of globin. However, FIT can be positive in excessive upper gastrointestinal bleeding.

\subsection{Guaiac-based fecal occult blood test (gFOBT)} Guaiac testing identifies hemoglobin by turning guaiac reagent-impregnated paper blue as the result of a peroxidase 
reaction. Guaiac testing of stool samples can identify hemoglobin that may be present due to bleeding from a colon lesion or for other reasons. gFOBT screening should only be performed using a highly sensitive guaiac reagent, such as Hemoccult SENSA, which has higher sensitivity than Hemoccult, Hemoccult-II, or Hemoccult-R, although it has lower specificity (Levin et al., 2008; Bibbins-Domingo et al, 2016).

A restrictive diet during gFOBT testing may not be necessary, although eliminating red meat for three days is recommended by the manufacturer (Pignone et al., 2001). Vitamin $C$ intake should be restricted to $<250 \mathrm{mg}$ per day for at least three days prior to sampling. Large doses of vitamin C may cause false-negative tests (Jaffe et al., 1975). Stool for gFOBT should not be obtained during digital rectal examination (DRE). DRE may induce microtrauma and cause a false-positive result. But there are contradictory results in some studies. In the laboratory, gFOBT samples should not be rehydrated prior to processing (Duffy et al., 2011). Hydration increases test sensitivity but leads to an increased number of false-positive results. Positive results may also occur with upper gastrointestinal bleeding.

\section{Causes of occult GI bleeding}

The differential diagnosis for occult GI bleeding is broad (Table 1 and Table 2). More common causes include colon cancer, esophagitis, peptic ulcers, gastritis, inflammatory bowel disease, vascular ectasias, portal hypertensive gastropathy, gastric antral vascular ectasias, and small bowel tumors (e.g., GI stromal cell tumor, lymphoma, carcinoid, adenocarcinoma, or polyp). Less common causes, such as gastroesophageal cancers, hemosuccus pancreaticus, hemobilia, endometriosis, and infections also need to be considered.

In persons younger than age 40, bleeding is more likely to be caused by a tumor, Meckel diverticulum, or Crohn disease. Angioectasias or an NSAID-induced ulcer are common causes in persons 40 years of age and older. Non-GI sources of blood loss, such as hemoptysis and epistaxis, can also cause a positive fecal occult blood test.

A positive fecal occult blood test should not be attributed to GI lesions that are infrequently associated with occult bleeding (e.g., esophageal varices and colonic diverticula). Patients with bleeding colonic diverticular disease present with overt, rather than occult, bleeding. In a patient with known esophagogastric varices or colonic diverticula, a positive test for occult blood or otherwise unexplained iron deficiency anemia should not preclude a diagnostic evaluation. Colonic diverticula commonly occur in the age bracket with the highest incidence of colon cancer.

Positive fecal occult blood tests in patients using antiplatelet agents and anticoagulants should not be assumed as false-positive. These patients should be evaluated (Sawhney et al., 2010).

The presence of fecal occult blood should not be attributed to alcohol ingestion alone unless coexistent pathology has been excluded.

The medical history and physical examination can help focus the differential diagnosis. Aortic valve stenosis (Heyde's syndrome), chronic kidney failure and some rheumatologic diseases may have bleeding due to angiodysplasia. Epistaxis and telangiectasias in the oral-nasal mucosa may indicate hereditary hemorrhagic telangiectasia. Hyperpigmented macules on the lips and oral mucosa (melanosis) suggest Peutz-Jeghers syndrome.

\section{Evaluation of a positive fecal occult blood test}

The evaluation of a patient with a positive fecal occult blood is presented in Fig. 1. (Perencevich and Saltzman, 2020). The prevalence of lesions in the upper GI tract is greater than or equal to that of colonic lesions. There may be both upper and lower GI lesions in some patients. Patients without iron deficiency anemia can be evaluated with colonoscopy, with or without upper endoscopy. Patients with iron deficiency anemia require a more extensive evaluation, including upper endoscopy and colonoscopy.

If upper endoscopy and colonoscopy do not reveal a source of the bleeding, the next step is evaluation of the small bowel. Repeat examinations probably have greatest value in patients with occult bleeding with iron deficiency anemia, or overt bleeding with melena or maroon blood per rectum. Repeat upper endoscopy or colonoscopy should be the first step in the evaluation if either examination was suboptimal when initially performed.

Obscure bleeding lesions (Fig. 2) that are commonly missed in the upper gastrointestinal tract include Cameron ulcers or erosions in a large hiatus hernia, peptic ulcers on the medial aspect of the junction of the bulb and second part of the duodenum, Dieulafoy lesions, gastric antral vascular ectasia (GAVE), and angioectasia. A side-viewing duodenoscope may be of value in examining the medial aspect of the second part of the duodenum and periampullary area. Some of the lesions that may be missed in the colon include colon cancer, angioectasia, diverticula, and inflammatory bowel disease (Raju et al., 2007; Bull-Henry and Al-Kawas, 2013; Vlachogiannakos et al., 2011).

While hemorrhoidal bleeding can lead to bleeding and anemia, but bleeding leading to iron deficiency anemia should not be attributed to hemorrhoids unless significant bleeding from hemorrhoids is reported by the patient, bleeding seen during an endoscopic evaluation, and other sources have been excluded. 
Table 1. Causes of occult gastrointestinal bleeding (Perencevich and Saltzman, 2020)

\begin{tabular}{|c|c|c|c|c|}
\hline $\begin{array}{l}\text { Inflammmatory/ } \\
\text { Mechanical trauma }\end{array}$ & Mass lesions any site) & Vascular & Infectious & Miscellaneous \\
\hline $\begin{array}{ll}\text { - } & \text { Reflux } \\
& \text { esophagitis } \\
\text { - } & \text { Cameron lesions } \\
\text { - } & \text { Erosive gastritis } \\
\text { - } & \text { Gastric ulcer } \\
\text { - } & \text { Duodenal ulcer } \\
\text { - } & \text { Whiac sprue } \\
\text { - } & \text { Meckel disease } \\
& \text { diverticulum } \\
\text { - } & \text { with ulceration } \\
& \text { Idiopathic cecal } \\
\text { - } & \text { ulcer } \\
\text { - } & \text { Crohn disease } \\
\text { Ulcerative } \\
\text { colitis }\end{array}$ & $\begin{array}{ll}\text { - } & \text { Carcinoma } \\
\text { - } & \text { Large polyps }\end{array}$ & $\begin{array}{ll}\text { - } & \text { Vascular } \\
\text { ectasia(s) } \\
\text { - } & \text { Portal } \\
\text { hypertensive } \\
\text { gastropathy } \\
\text { - } & \text { Portal } \\
\text { hypertensive } \\
\text { enteropathy and } \\
\text { colopathy } \\
\text { Gastric antral } \\
\text { vascular ectasia } \\
\text { - } & \text { Hemangiomas } \\
\text { Blue rubber bleb } \\
\text { nevus syndrome }\end{array}$ & $\begin{array}{ll}\text { - } & \text { Hookworm } \\
\text { - } & \text { Strongyloidiasis } \\
\text { - } & \text { Ascariasis } \\
\text { - } & \text { Tuvberculous } \\
& \text { enterocolitis } \\
\text { - } & \text { Amebiasis }\end{array}$ & $\begin{array}{ll}\text { - } & \text { Long-distance } \\
& \text { running } \\
\text { - } & \text { Factitious } \\
\text { - } & \text { Hemoptysis } \\
\text { - } & \text { Epistaxis } \\
\text { - } & \text { Oropharyngeal }\end{array}$ \\
\hline
\end{tabular}

Table 2. Causes of small bowel bleeding (Perencevich and Saltzman, 2020)

\begin{tabular}{|c|c|c|}
\hline \multicolumn{2}{|c|}{ Common causes } & \multirow{2}{*}{ Rare causes } \\
\hline Under age 40 years & Over age 40 years & \\
\hline $\begin{array}{ll}\text { - } & \text { Inflammmatory bowel disease } \\
\text { - } & \text { Meckel diverticulum } \\
\text { - } & \text { Dieulafoy lesions } \\
\text { - } & \text { Neoplasia } \\
\text { - } & \text { Polyposis syndrome }\end{array}$ & $\begin{array}{ll}\text { - } & \text { NSAID ulcers } \\
\text { - } & \text { Angioectasia } \\
\text { - } & \text { Dieulafoy lesions } \\
\text { - } & \text { Neoplasia }\end{array}$ & $\begin{array}{ll}\text { - } & \text { Henoch-Schonlein purpura } \\
\text { - } & \text { Small bowel varices and/or portal } \\
\text { - } & \text { Amyloidosis } \\
\text { - } & \text { Blue rubber bleb nevus syndrom } \\
\text { - } & \text { Pseudoxanthoma elasticum } \\
\text { - } & \text { Osler-Weber-Rendu syndrome } \\
\text { - } & \text { Kaposi sarcoma with AIDS } \\
\text { - } & \text { Plummer-Vinson syndrome } \\
\text { - } & \text { Ehkers-Danlos syndrome } \\
\text { - } & \text { Inherited polyposis syndromes (FAP, } \\
\text { - } & \text { Peutz-Jeghers) } \\
\text { - } & \text { Hemobignant atrophic papulosis } \\
\text { - } & \text { Aortoenteric fistula } \\
\text { - } & \text { Hemosuccus pancreaticus }\end{array}$ \\
\hline
\end{tabular}

FAP: familial adenomatous polyposis; NSAID: Nonsteroidal anti-inflammatory drug

A patient with a positive fecal occult blood test and no anemia should undergo a colonoscopy. If the patient has upper GI symptoms, an upper endoscopy should also be performed. If initial testing is negative and there are no signs of ongoing blood loss, further evaluation of these patients is not recommended.

A patient with a positive fecal occult blood test and iron deficiency anemia should undergo upper endoscopy and colonoscopy. If complete endoscopy and colonoscopy with adequate visualization do not reveal the source of the bleeding, small bowel evaluation is recommended. Wireless capsule endoscopy is of choice in the majority of patients. CT enterography, and magnetic resonance (MR) enterography are the alternatives of capsule endoscopy with similar or less sensitivity.

As bleeding continues deep small bowel enteroscopy is suggested. If there is any source and bleeding is going on additional testing like angiography, CT angiography, scintigraphy, Meckel's scan, or laparoscopy/laparotomy with intraoperative enteroscopy are recommended.
Capsule endoscopy is equally or more sensitive than other methods for the diagnosis of small bowel sources of blood loss. Capsule endoscopy is contraindicated in some patients, including those with partial or intermittent small bowel obstruction, women who are pregnant, and patients who are unable to swallow the capsule. The diagnostic yield of capsule endoscopy in patients with overt bleeding appears to be highest when it is performed as close as possible to the bleeding episode. Testing with a fecal immunochemical test (FIT) for occult blood may help with the timing of capsule endoscopy in patients with suspected small bowel bleeding.

Enteroscopy involves the passage of an adult or pediatric colonoscope or a special enteroscope beyond the ligament of Treitz. Several methods of enteroscopy have been described such as push, intraoperative, and deep small bowel enteroscopy like single balloon, double balloon, and spiral enteroscopy. In patients with a negative capsule endoscopy and computed tomographic (CT) enterography with ongoing bleeding, the next step in the evaluation is typically deep small bowel enteroscopy. All of the deep enteroscopy techniques allow for 
both evaluation and therapeutic intervention in the small bowel. Capsule-directed deep enteroscopy may be associated with better long-term outcomes because of fewer complications and decreased utilization of endoscopic resources.

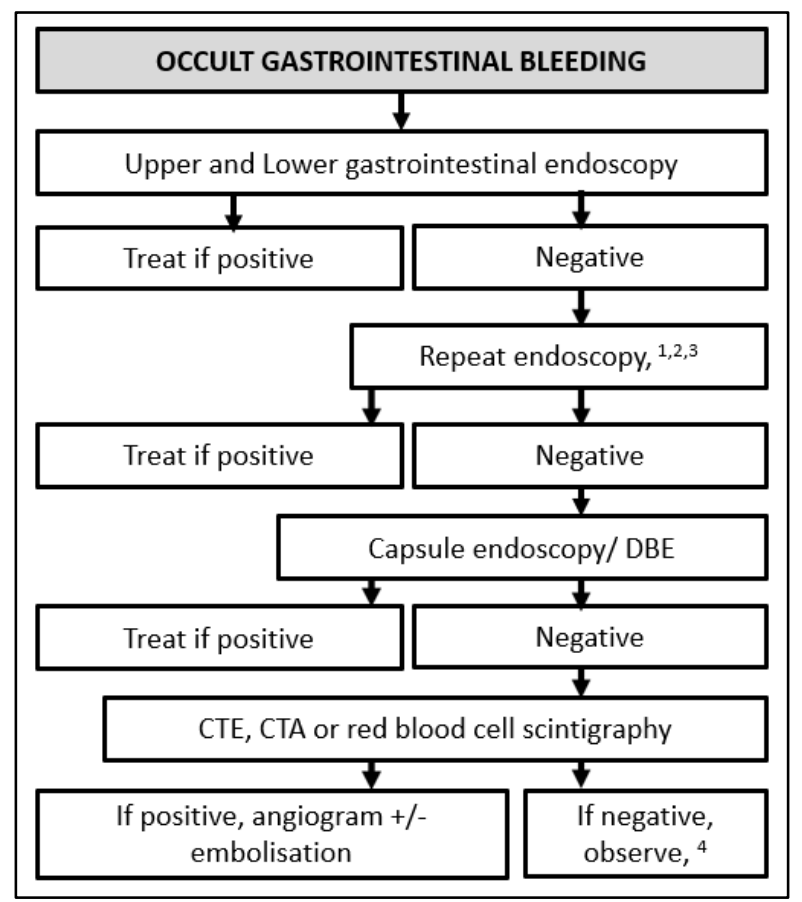

Fig. 1. Evaluation of occult gastrointestinal bleeding (Perencevich and Saltzman, 2020; Murphy et al., 2019) DBE; double balloon enteroscopy, CTE; computerised tomography enteroscopy. 1- If the initial endoscopy was inadequate, 2- If there are risk factors for hemobilia or hemosuccus pancreaticus, evaluate with side-viewing duodenoscope, 3- If there are risk factors for aortoenteric fistula, push enteroscopy, CT angiography, 4-Iron replacement if there is iron deficiency anemia

Intraoperative enteroscopy is an option if deep small bowel or push enteroscopy does not reveal a bleeding source, if there is massive bleeding with hemodynamic instability, or if there are contraindications to deep small bowel enteroscopy, such as dense abdominal adhesions. Intraoperative enteroscopy involves the insertion of an endoscope orally, rectally or through an enterotomy site during surgery. In general, intraoperative enteroscopy is avoided unless there is no known target established by endoscopy or imaging.

A radionuclide bleeding scan detects bleeding that is occurring at a minimum rate of 0.1 to $0.5 \mathrm{~mL} /$ minute. It is of little or no value in patients with gastrointestinal bleeding who appear clinically to have a low rate of blood loss (such as those with occult blood only) since the rate of bleeding is likely to be too slow to be detected. This technique only localize bleeding to an area of the abdomen. If a bleeding source is identified, additional interventions (such as angiography) are required.

A Meckel's scan consists of the intravenous administration of $99 \mathrm{mTc}$ pertechnetate, which has an affinity for gastric mucosa. The test does not detect active bleeding. Meckel's scan may reveal a potential bleeding source and is particularly appropriate in children and young adults.

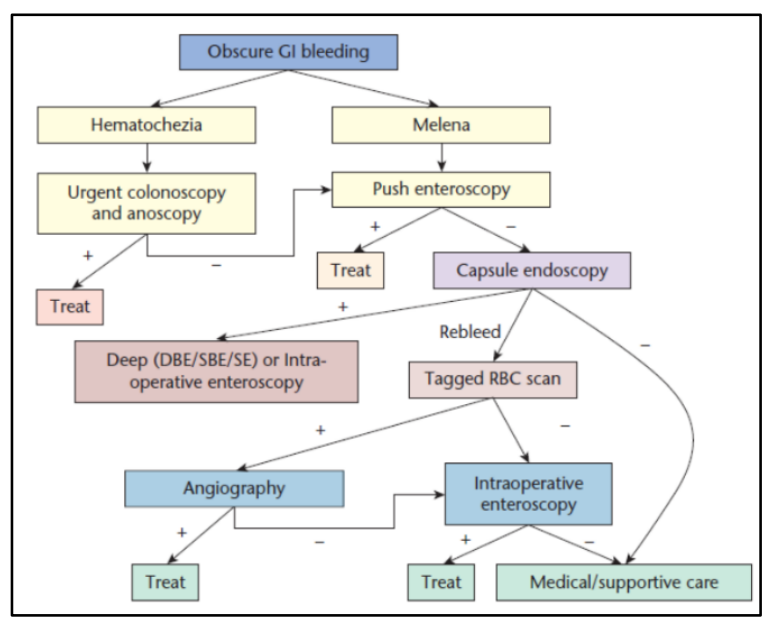

Fig. 2. Management of obscure gastrointestinal bleeding (Ghassemi et al., 2012). DBE; Double balloon enteroscopy, SBE; Single balloon enteroscopy, SE; spiral enteroscopy, RBC; red blood cell

\section{Evaluation of isolated iron deficiency anemia:}

Patients with unexplained iron deficiency anemia but a negative fecal occult blood test should be evaluated for a GI source of blood loss (Fig. 1.). Patients with isolated iron deficiency anemia should be evaluated for celiac disease if an alternative source of blood loss is not identified. If patients have symptoms suggesting either an upper or lower GI source, it is reasonable to start the evaluation with an upper endoscopy or colonoscopy, respectively (Rockey, 2010). For patients who are asymptomatic, a colonoscopy is often the first test obtained, but in patients with anemia, we suggest to start the evaluation with both an upper endoscopy and a colonoscopy. If both upper endoscopy and colonoscopy are negative, additional testing such as wireless capsule endoscopy should be pursued.

The optimal approach to iron deficiency anemia in women who continue to menstruate is uncertain. In one series, a clinically important lesion was detected in 23 of 186 premenopausal women (12 percent) who underwent endoscopy (Bini et al., 1998). Endoscopic evaluation should be obtained if a fecal occult blood test is positive, if the iron deficiency anemia is out of proportion to menstrual blood loss, if the patient has abdominal symptoms, or if the patient has a family history of GI malignancy in a first-degree relative, particularly if the patient is older than 40 years of age.

\section{Treatment of occult gastrointestinal bleeding:}

\subsection{Medical management}

Either intravenous or oral iron supplementation may be used in occult GI bleeding to maintain hemoglobin levels. In more acute or overt bleeding, red cell transfusion should be used where necessary (Murphy et al., 2019). GI bleeding will occur in $1-3 \%$ of patients taking anticoagulant therapy (Guerrouij et al., 2011). Holding these agents does not appear to lower the risk of recurrent bleeding, interestingly (Koh et al., 2013; Arakawa et al., 2009). Meta-analysis from 2014 shows benefit from the use of somatostatin analogs in patients with angiodysplasia but not hormonal therapy (Jackson and Gerson 2014). Thalidomide has been used successfully to treat patients with refractory GI bleeding. It is an angiogenesis 
inhibitor and is therefore most effective in treating patients with vascular etiology, such as angiodysplasia and AVMs (Ge et al., 2011).

Tranexamic acid has been shown to reduce mortality in bleeding trauma patients (Crash-2 Collaborators, 2011). A systematic review has found that it can reduce the probability of receiving a blood transfusion in up to $33 \%$ of acute GI bleed patients (Roberts et al., 2012).

\subsection{Interventional radiology and endoscopy}

If a bleeding lesion is noted on angiography, success rates have been reported in $60-90 \%$ of cases. The advent of newer techniques and superselective embolization has further improved success rates and decreased the risk of bowel infarction (Patel et al., 2001; Schenker et al., 2001). Angiodysplastic lesions are treated typically with Argon Plasma Coagulation to good initial effect but rebleeding rates are high.

\subsection{Surgery}

Diagnostic laparoscopy or laparotomy may be considered in small bowel GI bleeding where no other modality has demonstrated a source. Furthermore, it may be utilized when a bleeding point has been identified but is not amenable to endoscopic/radiological therapy or mandates resection e.g., Meckel's diverticulum or mass lesion (Murphy et al., 2019).

\section{Conflict of interest}

None.

\section{Acknowledgments}

None.

\section{References}

1. Arakawa, D., Ohmiya, N., Nakamura, M., Honda, W., Shirai, O., Itoh, A., Hirooka, Y., Niwa, Y., Maeda, O., Ando, T., Goto, H., 2009. Outcome after enteroscopy for patients with obscure GI bleeding: diagnostic comparison between double-balloon endoscopy and videocapsule endoscopy. Gastrointest. Endosc. 69, 866-874.

2. Bini, E.J., Micale, P.L., Weinshel, E.H., 1998. Evaluation of the gastrointestinal tract in premenopausal women with iron deficiency anemia. Am. J. Med. 105, 281.

3. Bull-Henry, K., Al-Kawas, F.H., 2013. Evaluation of occult gastrointestinal bleeding. Am. Fam. Physician. 87, 430.

4. Crash-2 Collaborators, 2011. The importance of early treatment with tranexamic acid in bleeding trauma patients: an exploratory analysis of the CRASH-2 randomised controlled trial. Lancet. 377, 1096-1101.

5. Doubeni, C., 2020. Tests for screening for colorectal cancer. UpToDate, Version 18.

6. Duffy, M.J., van Rossum, L.G., van Turenhout, S.T., Malminiemi, O., Sturgeon, C., Lamerz, R., Nicolini, A., Haglund, C., Holubec, L., Fraser, C.G., Halloran, S.P., 2011. Use of faecal markers in screening for colorectal neoplasia: A European group on tumor markers position paper. Int. J. Cancer. 128,3 .

7. Ge, Z.Z., Chen, H.M., Gao, Y.J., Liu, W.Z., Xu, C.H., Tan, H.H., Chen, H.Y., Wei, W., Fang, J.Y., Xiao, S.D., 2011. Efficacy of thalidomide for refractory gastrointestinal bleeding from vascular malformation. Gastroenterology. 141,1629-1637.
8. Ghassemi, K.A., Jensen, D.M., Jutabha, R., 2012. Gastrointestinal causes of anemia and occult bleeding. In, Hawkey CJ, Bosch J, Richter J, Garcia-Tsao G, Chan F, eds. Textbook of Clinical Gastroenterology and Hepatology, $2^{\text {nd }}$ ed, Wiley-Blackwell UK., 73-77.

9. Guerrouij, M., Uppal, C.S., Alklabi, A., Douketis, J.D., 2011. The clinical impact of bleeding during oral anticoagulant therapy. J. Thromb. 31, 419-423.

10. Huang, Y., Li, Q., Ge, W., Cai, S., Zhang, S., Zheng, S., 2014. Predictive power of quantitative and qualitative fecal immunochemical tests for hemoglobin in population screening for colorectal neoplasm. Eur. J. Cancer. Prev. 23, 27.

11. Jackson, C.S., Gerson, L.B., 2014. Management of gastrointestinal angiodysplastic lesions (GIADs): A systematic review and meta-analysis. Am. J. Gastroenterol. 109, 474.

12. Jaffe, R.M., Kasten, B., Young, D.S., MacLowry, J.D., 1975. False-negative stool occult blood tests caused by ingestion of ascorbic acid (vitamin C). Ann. Intern. Med. 83, 824.

13. Koh, S.J., Im, J.P., Kim, J.W., Kim, B.G., Lee, K.L., Kim, S.G., Kim, J.S., Jung, H.C., 2013. Longterm outcome in patients with obscure gastrointestinal bleeding after negative capsule endoscopy. World. J. Gastroenterol. 19, 1632.

14. Levin, B., Lieberman, D.A., McFarland, B., Smith, R.A., Brooks, D., Andrews, K.S., Dash, C., Giardiello, F.M., Glick, S., Levin, T.R., Pickhardt, P., Rex, D.K., Thorson, A., Winawer, S.J., 2008. Screening and surveillance for the early detection of colorectal cancer and adenomatous polyps, 2008: a joint guideline from the American Cancer Society, the US MultiSociety Task Force on Colorectal Cancer, and the American College of Radiology. C.A. Cancer. J. Clin. 58, 130.

15. Murphy, B., Winter, D.C., Kavanagh, D.O., 2019. Small bowel gastrointestinal bleeding diagnosis and management A narrative Review. Front. Surg. 6, 25.

16. Park, M.J., Choi, K.S., Lee, Y.K., Jun, J.K., Lee, H.Y., 2012. A comparison of qualitative and quantitative fecal immunochemical tests in the Korean national colorectal cancer screening program. Scand. J. Gastroenterol. 47, 461.

17. Patel, T.H., Cordts, P.R., Abcarian, P., Sawyer, M.A., 2001. Will transcatheter embolotherapy replace surgery in the treatment of gastrointestinal bleeding? Curr. Surg. 58, 323-327.

18. Perencevich, M., Saltzman, J.R., 2020. Evaluation of occult gastrointestinal bleeding. UpToDate, Version 18.

19. Pignone, M., Campbell, M.K., Carr, C., Phillips, C., 2001. Metaanalysis of dietary restriction during fecal occult blood testing. Eff. Clin. Pract. 4, 150.

20. Raju, G.S., Gerson, L., Das, A., Lewis, B., 2007. American Gastroenterological Association (AGA) Institute medical position statement on obscure gastrointestinal bleeding. Gastroenterology. 133,1694.

21. Roberts, I., Perel, P., Prieto-Merino, D., Shakur, H., Coats, T., Hunt, B.J., Lecky, F., Brohi, K., Willett, K., CRASH-2 Collaborators., 2012. Effect of tranexamic acid on mortality in patients with traumatic bleeding: prespecified analysis of data from randomised controlled trial. BMJ. 345, e5839.

22. Robertson, D.J., Lee, J.K., Boland, C.R., Dominitz, J.A., Giardiello, F.M., Johnson, D.A., Kaltenbach, T., Lieberman, D., Levin, T.R., Rex, D.K., 2017. recommendations on fecal immunochemical testing to screen for colorectal neoplasia: a consensus statement by the us multi-society task force on colorectal cancer. Gastroenterology. 152,1217.

23. Rockey, D.C., 2010. Occult and obscure gastrointestinal 


\section{Bektas / J Exp Clin Med}

bleeding: Causes and clinical management. Nat. Rev. Gastroenterol. Hepatol. 7, 265.

24. Sawhney, M.S., McDougall, H., Nelson, D.B., Bond, J.H., 2010. Fecal occult blood test in patients on low-dose aspirin, warfarin, clopidogrel, or non-steroidal anti-inflammatory drugs. Dig. Dis. Sci. 55,1637 .

25. Schenker, M.P., Duszak, R. J.r, Soulen, M.C., Smith, K.P., Baum, R.A., Cope, C., Freiman, D.B., Roberts, D.A., ShlanskyGoldberg, R.D., 2001. Shlansky-goldberg. upper gastrointestinal hemorrhage and transcatheter embolotherapy: clinical and technical factors impacting success and survival. J. Vasc. Int. Radiol. 12, 1263-1271.

26. Vlachogiannakos, J., Papaxoinis, K., Viazis, N., Kegioglou, A.,
Binas, I., Karamanolis, D., Ladas, S.D. 2011. Bleeding lesions within reach of conventional endoscopy in capsule endoscopy examinations for obscure gastrointestinal bleeding: is repeating endoscopy economically feasible? Dig. Dis. Sci. 56, 1763.

27. Wong, M.C., Ching, J.Y., Chan, V.C., Lam, T.Y., Shum, J.P., Luk, A.K., Wong, S.S., Ng, S.C., Ng, S.S., Wu, J.C., Chan, F.K., Sung, J.J., 2015. Diagnostic accuracy of a qualitative fecal immunochemical test varies with location of neoplasia but not number of specimens. Clin. Gastroenterol. Hepatol. 13,1472.

28. Young, G.P., Symonds, E.L., Allison, J.E., Cole, S.R., Fraser, C.G., Halloran, S.P., Kuipers, E.J., Seaman, H.E., 2015. Advances in fecal occult blood tests: the FIT revolution. Dig. Dis. Sci. 60, 609. 